\title{
Award-winning papers in 2010
}

Papers published in Bridge Engineering are eligible for awards from the Institution of Civil Engineers. Papers from any of the ICE journals can be nominated for several awards. In addition, each journal has awards dedicated to their specific subject area.

On Monday 24 October 2011, ICE president Peter Hansford presented awards to the following papers published in Bridge Engineering in 2010. The editorial panel nominated their best papers and an awards committee chaired by Barry Clarke allocated the award.

\section{John Henry Garrood King Medal}

The John Henry Garrood King Medal, for the best paper published by the ICE on tunnels, soil mechanics or bridges, was awarded to: Sanders PA, MacKenzie DK and Walker CJ (2010) Design and construction of the Fabian Way bridge superstructure. Proceedings of the Institution of Civil Engineers - Bridge Engineering 163(2): 49-58, http://dx.doi.org/10.1680/bren.2010.163.2.49.

\begin{abstract}
The Fabian Way Bridge crosses a dual carriageway in Swansea and forms part of a local express bus route. The bridge is a $71 \mathrm{~m}$ long, heavily skewed cable stayed structure with a single central spine beam. Cantilevers extending either side of the central spine beam support twin orthotropic decks that carry vehicle and pedestrian traffic. The deck is supported by a slender inclined mast with an unusual open cross-section. The superstructure design was developed in close collaboration with the end client, main contractor and steelwork sub-contractor as an alternative to the client's original design, and maximises offsite prefabrication and buildability while achieving a graceful yet striking new landmark. The paper presents an interesting case study describing the reasons for the selection of an all-steel deck as the preferred solution, along with special aspects of the detailed design including the buckling analysis of the mast. The paper also describes the positive impact on urban regeneration, as well as the construction of the bridge. Ways in which a very tight design and construction programme was achieved are also described, together with issues affecting long-term maintenance of the bridge.
\end{abstract}

\section{Overseas Prize}

The Overseas Prize, for the best paper received during the year on a subject connected with works carried out outside the British Isles, was awarded to: Morgenthal G and Yamasaki Y (2010) Behaviour of very long cable-stayed bridges during erection. Proceedings of the Institution of Civil Engineers - Bridge Engineering 163(4): 213-224, http://dx.doi.org/10.1680/bren.2010.163.4.213.

\section{Abstract}

Stonecutters Bridge and Sutong Bridge in China have pushed the world record for main span length of cable-stayed bridges to over $1000 \mathrm{~m}$. The design of these bridges, both located in typhoon-prone regions, was strongly influenced by wind effects during erection. Rigorous wind tunnel test programmes were devised and executed to determine the aerodynamic behaviour of the structures in the most critical erection conditions. Testing was augmented by analytical and numerical analyses to verify the safety of the structures throughout construction and to ensure that no serviceability problems would affect the erection process. This paper outlines the wind properties assumed for the bridge sites, the experimental test programme with some of its results, the dynamic properties of the bridges during freecantilevering erection and an assessment of their aerodynamic performance. The similarities and some revealing differences between the two bridges in terms of their dynamic response to wind action are also discussed.

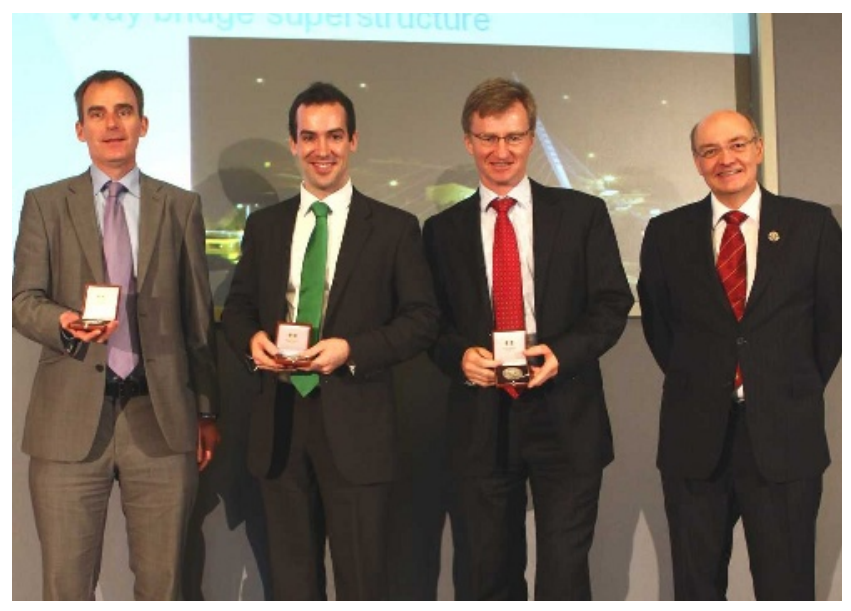

ICE President Peter Hansford presents the John Henry Garrood King Medal to Paul Sanders, David MacKenzie and Chris Walker 